\title{
Reflexões sobre a atuação do nutricionista no Programa Nacional de Alimentação Escolar no Brasil
}

\author{
Reflections on the activities of nutritionists \\ on the Brazilian School Nutrition Program
}

Lorena Gonçalves Chaves ${ }^{1}$

Thais Cristina Mantovani Santana ${ }^{2}$

Cristine Garcia Gabriel ${ }^{3}$

Francisco de Assis Guedes de Vasconcelos ${ }^{4}$
${ }^{1}$ Fundo Nacional de Desenvolvimento da Educação, Coordenação de Segurança Alimentar e Nutricional, Centro Colaborador de Alimentação e Nutrição. SBS Qd. 02, Bl. F, Ed. FNDE. 70070-929 Brasília DF.

lorena.chaves@fnde.gov.br ${ }^{2}$ Núcleo de Apoio à Saúde da Família, Secretaria de Estado de Saúde do Distrito Federal. ${ }^{3}$ Programa de PósGraduação em Saúde Coletiva, Universidade Federal de Santa Catarina. ${ }^{4}$ Departamento de Nutrição, Universidade Federal de Santa Catarina.

\begin{abstract}
The scope of this study is to reflect on the activities of nutritionists in the Brazilian School Nutrition Program, with emphasis on the number of professionals and the attributes, advances and challenges facing these professionals. A critical analysis was conducted based on a review of the literature and official data provided by the National Fund for the Development of Education (NFED) of the Brazilian Ministry of Education. Between the years 2003 to 2011, the percentage of Brazilian municipalities with nutritionists rose from $12 \%$ to $79 \%$. The northern region had the lowest percentage of local municipalities covered by nutritionists registered with the NFED (59\%) in 2011 and the southern region had the highest percentage (85\%), while the national average was $79 \%$. The findings reflect a certain inequality in the distribution of nutritionists among the different regions of Brazil. The diverse activities of these professionals in the Program suggest the need for ongoing updating and training. It is also necessary to comply with and monitor the numerical parameters of reference for hiring nutritionists in the different municipalities and states of the country.
\end{abstract}

Key words Nutritionist, School food, Nutrition and food programs and policies, Area of professional activity
Resumo O objetivo deste artigo é refletir sobre a atuação do nutricionista no Programa Nacional de Alimentação Escolar (PNAE), com ênfase no número de profissionais, nas atribuições e nos avanços e desafios do profissional. Ensaio crítico realizado com base em revisão da literatura e em dados oficiais fornecidos pelo Fundo Nacional de Desenvolvimento da Educação/Ministério da Educação (FNDE/MEC). Entre os anos de 2003 a 2011, o percentual de municípios brasileiros com nutricionistas cadastrados no PNAE/FNDE cresceu de 12\% para 79\%. Em 2011, dentre as regiões do país, a região Norte é a que apresentava o menor percentual de municípios cobertos por nutricionistas cadastrados (59\%), a região Sul apresentava o maior valor (85\%), enquanto que a cobertura nacional foi de $79 \%$. Os resultados encontrados refletem desigualdade na distribuição dos profissionais entre as regiões. As diversas atividades do profissional no Programa sugerem a necessidade de constante atualização e formação do nutricionista atuante no PNAE. É necessário também o cumprimento e a fiscalização dos parâmetros numéricos de referência para contratação de nutricionistas nos distintos municípios e estados brasileiros.

Palavras-chave Nutricionista, Alimentação escolar, Programas e políticas de nutrição e alimentação, Área de atuação profissional 


\section{Introdução}

O marco instituinte do Programa Nacional de Alimentação Escolar (PNAE) no Brasil remete ao ano de 1955, quando foi assinado o Decreto ${ }^{\circ} 37.106^{1}$, implementando no país a Campanha de Merenda Escolar, subordinada ao Ministério da Educação (MEC). Após alterações no nome e na vinculação institucional do PNAE, incluindo a superposição de diferentes órgãos ${ }^{2}$, vale pontuar que, a partir de 1983, a Fundação de Assistência ao Estudante (FAE/ MEC) encarregou-se do gerenciamento do Programa, tendo estimulado o início do processo de municipalização/descentralização do mesmo. A FAE foi extinta em 1997 e seus programas foram incorporados pelo Fundo Nacional de Desenvolvimento da Educação (FNDE), autarquia federal vinculada ao MEC, que apresenta como principal atividade a assistência financeira a projetos e programas da educação básica das escolas públicas ${ }^{3}$.

Ao decorrer de quase sessenta anos de existência, o PNAE é o programa socioeducacional brasileiro com mais longa história no campo de segurança alimentar e nutricional, sendo caracterizado, desde seus primórdios, por grandes quantitativos em termos de orçamento e cobertura populacional ${ }^{4,5}$. Concomitante às modificações nas suas estratégias de execução, os dispositivos legais que regulamentam o Programa também têm passado por revisões e atualizações ${ }^{4}$.

Após quatro décadas da instituição do Programa, o nutricionista foi apontado como o profissional responsável pela elaboração dos cardápios dos programas de alimentação escolar. Inserção oficializada pela Lei ${ }^{\circ} 8.913 / 1994$, que estabeleceu também a descentralização do Programa para estados, Distrito Federal e municípios ${ }^{6}$. Ainda com relação à atuação do nutricionista no PNAE, fato de destaque ocorreu no ano de 2006, quando a instituição da Resolução $n^{\circ} 32$ pelo FNDE normatizou que esse profissional deveria assumir a responsabilidade técnica pelo Programa ${ }^{7}$.

Os dispositivos legais supracitados foram revogados, estando atualmente em vigor os princípios e diretrizes dispostos na Lei ${ }^{\circ} 11.947 / 2009^{8}$, normatizada pela Resolução n 38/2009/FNDE 9 . De acordo com esses últimos dispositivos, o objetivo do PNAE é contribuir para o crescimento e o desenvolvimento biopsicossocial, a aprendizagem, o rendimento escolar e a formação de hábitos alimentares saudáveis dos alunos de toda a educação básica pública, por meio de ações de educação alimentar e nutricional e da oferta de refeições que cubram as suas necessidades nutricionais durante o período letivo ${ }^{8,9}$.
A Lei n ${ }^{\circ} 11.947 / 2009^{8}$, além de reforçar que a coordenação das ações de alimentação escolar deve ser realizada por nutricionista, dispõe também que o profissional deverá estar obrigatoriamente cadastrado no FNDE e vinculado ao setor de alimentação escolar da Entidade Executora (EE).

Com base em revisão da literatura e em dados oficiais fornecidos pelo FNDE/MEC, o presente artigo tem por objetivo refletir sobre a atuação do nutricionista na alimentação escolar. Busca-se discutir aspectos relacionados à evolução deste profissional no Programa ao longo dos anos, com ênfase no número de profissionais, nas atribuições e nos avanços e desafios do Responsável Técnico (RT) pelo Programa.

Um breve histórico da inserção

do nutricionista no PNAE (1954 a 2012):

evolução do número de profissionais

Evidências históricas atestam que desde o início do processo de idealização e institucionalização da política de alimentação escolar no Brasil, ocorrido entre os anos 1940-1955, foi observada relevante participação de médicos nutrólogos e nutricionistas. Liderados por Josué de Castro, vários nutrólogos e nutricionistas participaram do processo de construção da política de alimentação escolar brasileira, tanto no desenvolvimento de estudos e pesquisas sobre o tema, como na gestão e/ou execução das agências e instituições responsáveis pela implementação desta modalidade de política pública ${ }^{10-12}$.

Em detrimento das evidências históricas sobre a remota inserção/atuação do nutricionista nos órgãos de planejamento, gestão e execução do PNAE nos diferentes níveis hierárquicos de organização do programa (central, regional, local) dentro das três esferas administrativas (federal, estadual e municipal ${ }^{10-12}$, a institucionalização da inserção/atuação deste profissional no PNAE, com base em dispositivos legais, é um processo recente, verificado a partir dos primeiros anos da década de $1990^{6}$.

Vale destacar que esta importante conquista para a categoria profissional deve ser compreendida como produto do processo histórico de organização, mobilização e luta pela regulamentação e legitimidade da profissão de nutricionista no país. Ressalta-se que a profissão foi regulamentada pela Lei ${ }^{\circ} 5.276$, de 24 de abril de 1967, a qual foi revogada pela Lei $n^{\circ} 8.234$, de 17 de setembro de 1991, atualmente em vigor. Destaca-se ainda a aprovação da Lei no 6.583 , de 20 de outubro de 1978, que cria os Conselhos Federal e 
Regionais de Nutricionistas (CFN/CRN), regula seu funcionamento, e dá outras providências. Sendo assim, com a criação do sistema CFN/ $\mathrm{CRN}$, os nutricionistas brasileiros passam a dispor de um órgão específico com a finalidade de fiscalizar o exercício da profissão, organizar, disciplinar e desenvolver a categoria e lutar pelos seus interesses ${ }^{13}$.

Deste modo, a institucionalização da inserção do nutricionista no PNAE configurou-se inicialmente pela Lei no 8.913 , de 12 de julho de 1994, a qual foi marcante na história do Programa, além de instituir a descentralização dos recursos, condicionada à criação dos Conselhos de Alimentação Escolar (CAEs). Essa Lei em seu artigo $4^{\circ}$ dispunha que: a elaboração dos cardápios dos programas de alimentação escolar, sob a responsabilidade dos Estados e Municípios, através de nutricionista capacitado, será desenvolvida em acordo com o CAE, e respeitará os hábitos alimentares de cada localidade, sua vocação agrícola e a preferência pelos produtos in natura [grifo nosso] ${ }^{6}$.

Na sequência, por meio da Medida Provisória 2.178-36, de 24 de agosto de $2001^{14}$, que revogou a Lei $\mathrm{n}^{\circ} 8.913 / 1994^{6}$, o Programa passou a ter novo direcionamento, incorporando à sua base legal a possibilidade das EE descentralizarem a execução do PNAE por meio da escolarização. Essa medida possibilitou aos estados e municípios a transferência dos recursos diretamente às escolas. A descentralização certamente trouxe mudanças significativas na operacionalização do Programa, com consequências positivas para a qualidade do serviço ${ }^{3}$. Em relação ao nutricionista, a Medida Provisória 2.178-36/2001 manteve a responsabilidade do profissional na elaboração dos cardápios da alimentação escolar, ainda com a participação do $\mathrm{CAE}^{14}$.

A partir de 2003, no início do Governo Lula, com a Estratégia Fome Zero ${ }^{15}$, o PNAE passa a ter destaque como um dos programas de governo que visa à formação de hábitos alimentares saudáveis e à segurança alimentar e nutricional dos escolares ${ }^{3}$. Nesse mesmo período, a coordenação do Programa passa a ter, pela primeira vez, um nutricionista como principal gestor do Programa, em nível central. A presença deste profissional à frente do Programa, com a inserção de outros nutricionistas à equipe técnica, trouxe contribuições significativas para o PNAE. Esse novo cenário acarretou avanços e apontamentos importantes nas resoluções do FNDE que normatizam o Programa, tais como: ampliação das atribuições do nutricionista atuante no PNAE; exigência, por meio de ofícios e visitas orientadoras para a contratação do profissional como RT nas EE, atuação realizada em conjunto com o CFN; bem como exigências técnicas para elaboração de cardápios, como a obrigatoriedade de inserção de frutas e hortaliças e a restrição ao açúcar, sódio e gordura saturada ${ }^{7,16}$.

Visando orientar e normatizar as atividades que cabem ao nutricionista que atua no PNAE, foi publicada a Resolução do CFN no 358, de 18 de maio de $2005^{16}$. Paralelamente, a Resolução do CD/FNDE $n^{\circ} 32$, de 10 de agosto de $2006^{7}$, estabeleceu que o nutricionista deverá assumir a responsabilidade técnica pelo Programa, ou seja, deverá acompanhá-lo desde a aquisição dos alimentos até a sua distribuição ao aluno, corroborando e complementando o que o CFN já havia estabelecido.

Especificamente em relação ao quantitativo adequado de nutricionistas no PNAE, por EE, a normativa em vigor que apresenta os parâmetros numéricos mínimos de referência para atuação do profissional é a Resolução do CFN no 465, publicada em 23 de agosto de $2010^{17}$. Esta contém uma tabela única para toda a Educação Básica (educação infantil - creche e pré-escola; ensino fundamental; ensino médio e educação de jovens adultos), uma vez que atualmente todas as etapas e as modalidades de ensino são atendidas pelo PNAE (Tabela 1).

Tabela 1. Parâmetros numéricos mínimos de referência para contratação de nutricionistas, por unidade executora do Programa Nacional de Alimentação Escolar, para a educação básica.

\begin{tabular}{lcc}
\hline \multicolumn{1}{c}{ No de alunos } & No de nutricionistas & $\begin{array}{c}\text { Carga horária técnica } \\
\text { mínima recomendada }\end{array}$ \\
\hline Até 500 & 1 Responsável Técnico (RT) & 30 horas \\
501 a 1.000 & $1 \mathrm{RT}+1$ Quadro Técnico $(\mathrm{QT})$ & 30 horas \\
1.001 a 2.500 & $1 \mathrm{RT}+2 \mathrm{QT}$ & 30 horas \\
2.501 a 5.000 & $1 \mathrm{RT}+3 \mathrm{QT}$ & 30 horas \\
Acima de 5.000 & $1 \mathrm{RT}+3 \mathrm{QT}$ e +1 QT a cada fração de 2.500 alunos & 30 horas
\end{tabular}

Fonte: Resolução do Conselho Federal de Nutricionistas (CFN) no 465/2010. 
Como forma de acompanhamento das referidas Resoluções, a partir de 2005, a Coordenação Geral do PNAE/FNDE tem cadastrado os profissionais que atuam no Programa de forma constante e sistemática, por meio de formulários que devem ser enviados a essa Coordenação, devidamente assinados e identificados pelos nutricionistas - tanto o RT, quanto o Quadro Técnico (QT) destes profissionais e seus respectivos gestores.

Dessa forma, são realizados levantamentos anuais dos dados cadastrados por meio do Sistema de Cadastro de Nutricionistas (SINUTRI) do FNDE, que possibilita atualizações e constatações de possíveis inconsistências comparadas às normativas vigentes, além de monitoramento e interação com os nutricionistas que atuam na alimentação escolar, em busca do aprimoramento da execução conjunta do PNAE. O SINUTRI possibilita também o envio de relatórios ao CFN para que este, por sua vez, realize seu acompa- nhamento e fiscalização da atuação do profissional nas EE.

As Tabelas 2 e 3 demonstram a evolução dos quantitativos dos nutricionistas cadastrados no sistema do FNDE ao longo dos anos 2003-2011 e de acordo com as regiões do Brasil. O período analisado mostra que o percentual de municípios brasileiros com nutricionistas cresceu de $12 \%$ para 79\%, entre os anos de 2003 a 2011. Concomitantemente, destaca-se a evolução decrescente da quantidade de municípios sem nutricionistas (Tabela 2). Apesar desse importante decréscimo, e considerando-se que o número de nutricionistas cadastrados no PNAE/FNDE é maior que o número de municípios do Brasil, ressalta-se que em 2011 havia no país 1.145 municípios sem nutricionista atuando no PNAE (20\% dos municípios brasileiros). Ainda com relação à Tabela 2, destaca-se que a queda nos valores percentuais de municípios com nutricionistas cadastrados,

Tabela 2. Evolução do número de nutricionistas cadastrados no PNAE/FNDE, percentual de municípios (incluindo o Distrito Federal) com nutricionistas registrados e número e percentual de municípios sem nutricionistas cadastrados, no período de 2003 a 2011.

\begin{tabular}{lcccc}
\hline Ano & $\begin{array}{c}\text { No de } \\
\text { nutricionistas } \\
\text { cadastrados no } \\
\text { PNAE/FNDE }\end{array}$ & $\begin{array}{c}\text { \% de municípios com } \\
\text { nutricionistas } \\
\text { cadastrados no PNAE/ } \\
\text { FNDE (N = 5.564) }\end{array}$ & $\begin{array}{c}\text { No de municípios } \\
\text { sem nutricionistas } \\
\text { cadastrados no PNAE/ } \\
\text { FNDE (N = 5.564) }\end{array}$ & $\begin{array}{c}\text { \% de municípios sem } \\
\text { cadastrados no PNAE/ } \\
\text { FNDE (N = 5.564) }\end{array}$ \\
\hline 2003 & 813 & 12,0 & 4897 & 88,0 \\
2005 & 1.006 & 18,0 & 4.562 & 82,0 \\
2006 & 2.511 & 47,0 & 2949 & 53,0 \\
2007 & 3.162 & 64,0 & 2003 & 36,0 \\
2008 & 3.650 & 68,0 & 1780 & 32,0 \\
$2009 / 2010$ & 4.479 & 82,0 & 1.002 & 18,0 \\
2011 & 6.218 & 79,0 & 1.145 & 20,6 \\
\hline
\end{tabular}

Fonte: Elaborada a partir dos dados fornecidos pelo Sistema de Cadastro de Nutricionistas (SINUTRI) do Programa Nacional de Alimentação Escolar (PNAE)/Fundo Nacional de Desenvolvimento da Educação (FNDE), 2011.

Tabela 3. Número de nutricionistas e percentual de municípios (incluindo o Distrito Federal) cobertos com nutricionistas cadastrados no PNAE/FNDE, por região do Brasil no ano de 2011.

\begin{tabular}{lcc}
\hline $\begin{array}{c}\text { Região } \\
\text { (número de municípios) }\end{array}$ & $\begin{array}{c}\text { No de nutricionistas } \\
\text { cadastrados no PNAE/FNDE }\end{array}$ & $\begin{array}{c}\text { \% de municípios cobertos por } \\
\text { nutricionistas cadastrados no PNAE/FNDE }\end{array}$ \\
\hline Norte $(\mathrm{n}=449)$ & 375 & 59,4 \\
Nordeste $(\mathrm{n}=1.794)$ & 1.907 & 79,3 \\
Centro-Oeste $(\mathrm{n}=466)$ & 522 & 78,3 \\
Sudeste $(\mathrm{n}=1.668)$ & 2.002 & 81,4 \\
Sul ( $\mathrm{n}=1.188)$ & 1.412 & 84,5 \\
Brasil ( $\mathrm{n}=5.565)$ & 6.218 & 79,4 \\
\hline
\end{tabular}

Fonte: Elaborada a partir dos dados fornecidos pelo Sistema de Cadastro de Nutricionistas (SINUTRI) do Programa Nacional de Alimentação Escolar (PNAE)/Fundo Nacional de Desenvolvimento da Educação (FNDE), 2011. 
observada na transição dos anos de 2009/2010 para 2011, pode ter ocorrido em função de limitações operacionais do SINUTRI, somadas ao aumento de ações de capacitação e fiscalização por parte dos órgãos competentes, como os CRN. Além disso, ressalta-se ainda que muitos nutricionistas deixavam de atuar no Programa e não se desvinculavam oficialmente, gerando conflitos no Sistema.

Dentre as regiões do país, a região Norte era a que apresentava o menor percentual de municípios cobertos por nutricionistas cadastrados no PNAE/FNDE (59\%) em 2011, a região Sul apresentava o maior valor (85\%), enquanto que a cobertura nacional (Brasil) foi de 79\%. As demais regiões se aproximavam bastante do percentual apresentado pela região Sul (Tabela 3). A Tabela 4, por sua vez, apresenta a distribuição dos municípios cobertos pelo profissional, conforme as
Unidades Federativas do Brasil. A Tabela 4 evidencia que, com exceção dos estados do Amapá, Amazonas, Pernambuco, Roraima e Tocantins onde a cobertura do nutricionista no PNAE pode ser considerada baixa -, nas 22 demais Unidades Federativas a cobertura é quase igual ou superior àquela verificada para o contexto nacional.

\section{Atividades e atribuições do nutricionista no PNAE: uma síntese da Resolução ${ }^{\circ}$ 465/2010 do Conselho Federal de Nutricionistas}

Em dezembro de 2005, o CFN instituiu a Resolução $\mathrm{n}^{\circ} 380^{18}$, a qual dispõe sobre a definição das áreas de atuação do nutricionista e suas atribuições e estabelece parâmetros numéricos de referência, por área de atuação. Na ocasião, foram estabelecidas sete áreas de atuação, a saber: Alimentação Coletiva, Nutrição Clínica, Saúde

Tabela 4. Número de nutricionistas e percentual de municípios cobertos com nutricionistas cadastrados no PNAE/ FNDE, por unidade federativa do Brasil no ano de 2011.

\begin{tabular}{|c|c|c|}
\hline $\begin{array}{l}\text { Unidade da Federação } \\
\text { (número de municípios) }\end{array}$ & $\begin{array}{l}\text { No de nutricionistas } \\
\text { cadastrados no PNAE/FNDE }\end{array}$ & $\begin{array}{c}\text { No e \% de municípios cobertos por } \\
\text { nutricionistas cadastrados no PNAE/FNDE }\end{array}$ \\
\hline Acre $(n=22)$ & 22 & $17(77,3 \%)$ \\
\hline Alagoas $(\mathrm{n}=102)$ & 113 & $86(84,3 \%)$ \\
\hline Amapá $(\mathrm{n}=16)$ & 38 & $7(43,7 \%)$ \\
\hline Amazonas $(n=62)$ & 12 & $27(43,5 \%)$ \\
\hline Bahia $(\mathrm{n}=417)$ & 463 & $328(78,7 \%)$ \\
\hline Ceará $(\mathrm{n}=184)$ & 206 & $155(84,2 \%)$ \\
\hline Distrito Federal $(\mathrm{n}=1)$ & 28 & $1(100,0 \%)$ \\
\hline Espírito Santo $(\mathrm{n}=78)$ & 129 & $71(91,0 \%)$ \\
\hline Goiás $(\mathrm{n}=246)$ & 253 & $188(76,4 \%)$ \\
\hline Maranhão (n = 217) & 242 & $170(78,3 \%)$ \\
\hline Mato Grosso $(\mathrm{n}=141)$ & 153 & $110(78,0 \%)$ \\
\hline Mato Grosso do Sul $(\mathrm{n}=78)$ & 88 & $66(84,6 \%)$ \\
\hline Minas Gerais $(\mathrm{n}=853)$ & 934 & $667(78,2 \%)$ \\
\hline Pará $(\mathrm{n}=143)$ & 152 & $105(73,4 \%)$ \\
\hline Paraíba $(\mathrm{n}=223)$ & 207 & $164(73,5 \%)$ \\
\hline Paraná (n = 399) & 426 & $322(80,7 \%)$ \\
\hline Pernambuco $(\mathrm{n}=185)$ & 193 & $31(16,8 \%)$ \\
\hline Piauí ( $\mathrm{n}=224)$ & 227 & $172(76,8 \%)$ \\
\hline Rio de Janeiro $(\mathrm{n}=92)$ & 192 & $80(86,9 \%)$ \\
\hline Rio Grande do Norte $(\mathrm{n}=167)$ & 171 & $136(81,4 \%)$ \\
\hline Rio Grande do Sul $(\mathrm{n}=496)$ & 634 & $439(88,5 \%)$ \\
\hline Rondônia $(\mathrm{n}=52)$ & 56 & $39(75,0 \%)$ \\
\hline Roraima $(\mathrm{n}=15)$ & 13 & $8(53,3 \%)$ \\
\hline Santa Catarina $(n=293)$ & 352 & $244(83,3)$ \\
\hline São Paulo $(\mathrm{n}=645)$ & 747 & $540(83,7 \%)$ \\
\hline Sergipe $(\mathrm{n}=75)$ & 85 & $59(78,7 \%)$ \\
\hline Tocantins $(\mathrm{n}=139)$ & 82 & $64(46,0 \%)$ \\
\hline $\operatorname{Brasil}(\mathrm{n}=5.565)$ & 6.218 & $4.419(79,4 \%)$ \\
\hline
\end{tabular}

Fonte: Elaborada a partir dos dados fornecidos pelo Sistema de Cadastro de Nutricionistas (SINUTRI) do Programa Nacional de Alimentação Escolar (PNAE)/Fundo Nacional de Desenvolvimento da Educação (FNDE), 2011. 
Coletiva, Docência, Indústria de Alimentos, Nutrição em Esporte e Marketing na área de Alimentação e Nutrição. Na referida Resolução, as atividades e atribuições do nutricionista em Alimentação Escolar se constituiu uma subárea da área "Alimentação Coletiva"18.

Ressalta-se, entretanto, que desde maio de 2005, o CFN já havia publicado outro instrumento normativo - a Resolução no $358^{16}$, que visava estabelecer as atribuições do nutricionista especificamente no âmbito do PNAE.

Na época, a Resolução no 358/2005 ${ }^{16}$ foi considerada um importante instrumento para orientar e normatizar as atividades que deveriam ser realizadas pelo nutricionista atuante na alimentação escolar. No entanto, essa Resolução precisou ser revista cerca de cinco anos após sua publicação devido às modificações ocorridas na legislação do PNAE, especialmente no ano de $2009^{8,9}$.

Nesta perspectiva, torna-se necessário apontar alguns dos principais avanços ocasionados com a publicação da Lei $n^{\circ} 11.947 / 2009^{8}$. Esta ampliou o PNAE para toda a rede pública de educação básica e estabeleceu que, do total dos recursos financeiros repassados pelo FNDE, no mínimo 30\% deve ser utilizado na aquisição de gêneros alimentícios diretamente da agricultura familiar e do empreendedor familiar rural ou suas organizações locais. Tais características ocasio- naram, obrigatoriamente, modificações nas usuais atribuições do nutricionista no PNAE, resultando na publicação da Resolução CFN nº 465/ $2010^{17}$, que revogou as disposições anteriores e atualizou as atribuições do profissional, em consonância com as normativas federais em vigor $^{8,9}$. Atividades anteriormente não delegadas ao nutricionista passaram a fazer parte do rol de atribuições previstas na rotina desse profissional.

O Quadro 1 relaciona as atividades técnicas obrigatórias do nutricionista no âmbito do PNAE, conforme a Resolução no 465/2010/ $\mathrm{CFN}^{17}$. Comparando-se a antiga Resolução $\mathrm{n}^{\circ}$ $358 / 2005^{16}$ com a atual ${ }^{17}$, observa-se o aparecimento de novas atribuições. Como exemplo, destaca-se o fato de que a partir da Resolução CFN $n^{\circ} 465 / 2010^{17}$, esse profissional deparou-se com a necessidade de interagir com os agricultores familiares e empreendedores familiares rurais e suas organizações, de forma a conhecer a produção local e assim inserir esses produtos nos cardápios escolares ${ }^{8,9}$.

Além disso, a Resolução CFN no 465/2010 ${ }^{17}$ enfatiza a necessidade de realizar o acompanhamento do estado nutricional dos escolares e não somente o diagnóstico. Esse item também se relaciona com aumento na carga de trabalho do nutricionista, uma vez que essas atividades devem agora englobar as etapas e a modalidade de

Quadro 1. Atribuições obrigatórias do nutricionista no âmbito do Programa de Alimentação Escolar, conforme a Resolução no 465 de 23 de agosto de 2010 do Conselho Federal de Nutricionistas (CFN).

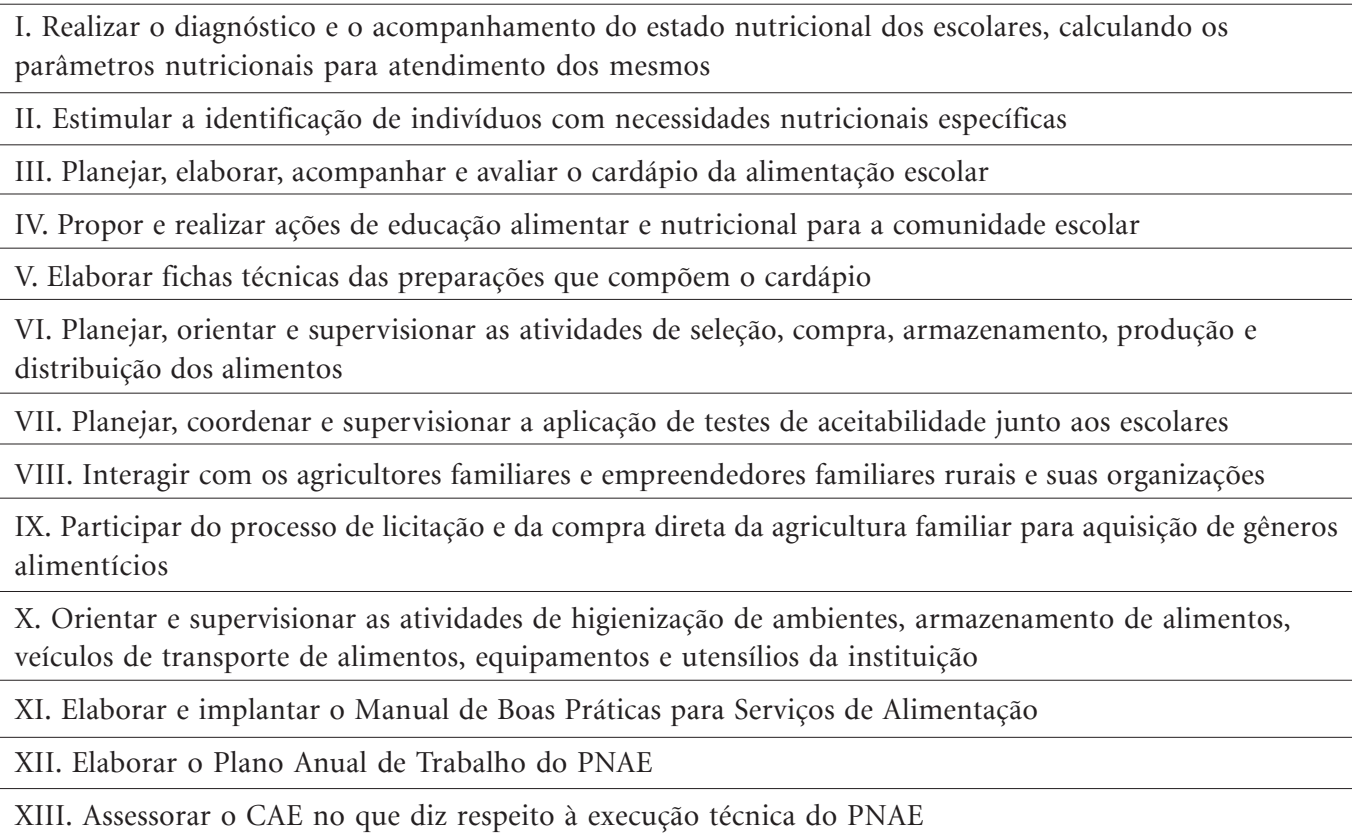


ensino de Educação de Jovens e Adultos da educação básica, subsidiando os cálculos dos parâmetros nutricionais, em consonância com parâmetros definidos em normativas do FNDE9.

Destaca-se também que todas as antigas atribuições previstas na Resolução no $358 / 2005^{16}$ foram mantidas, sofrendo somente pequenos ajustes de forma/conteúdo, os quais não interferiram ou suprimiram atividades previamente delegadas ao profissional. Isso reflete na necessidade de constante atualização e formação do nutricionista atuante no PNAE.

Percebe-se que as atividades descritas no Quadro 1 corroboram e complementam o estabelecido no $\$ 1^{\circ}$ do art. 14 da Resolução n 38/2009/ FNDE$^{9}$, a qual dispõe que compete ao nutricionista responsável técnico pelo Programa, e aos demais nutricionistas lotados no setor de alimentação escolar, coordenar o diagnóstico e o monitoramento do estado nutricional dos estudantes, planejar o cardápio da alimentação escolar de acordo com a cultura alimentar, o perfil epidemiológico da população atendida e a vocação agrícola da região, acompanhando desde a aquisição dos gêneros alimentícios até a produção e distribuição da alimentação, bem como propor e realizar ações de educação alimentar e nutricional nas escolas.

Considerando-se que uma importante atribuição obrigatória do nutricionista no PNAE refere-se à elaboração, acompanhamento e avaliação do cardápio da alimentação escolar (Quadro 1), torna-se oportuno citar também o estabelecido pelo art. 12 da Lei $\mathrm{n}^{\circ} 11.947 / 2009^{8}$ que dispõe que: os cardápios da alimentação escolar deverão ser elaborados com utilização de gêneros alimentícios básicos, respeitando-se as referências nutricionais, os hábitos alimentares, a cultura alimentar da localidade, pautando-se na sustentabilidade e diversificação agrícola da região e na alimentação saudável e adequada.

Além das atividades obrigatórias, a Resolução CFN no $465 / 2010^{17}$ dispõe que compete ao nutricionista algumas atividades complementares, como por exemplo: participar de equipes multidisciplinares destinadas a planejar e executar políticas, programas, cursos, pesquisas e eventos na área de alimentação escolar; contribuir na elaboração e revisão das normas reguladoras próprias da área e; colaborar na formação de profissionais na área de alimentação e nutrição.

\section{Desafios e perspectivas futuras para o nutricionista que atua no PNAE}

Os dados apresentados nesse artigo demonstram que o percentual de municípios brasileiros com nutricionistas cadastrados no FNDE/PNAE tem evoluído ao longo dos últimos anos. Se inicialmente a atuação do nutricionista limitava-se à elaboração do cardápio, logo foram incorporadas muitas outras atividades técnicas ${ }^{9,17}$ na rotina do profissional, as quais ampliaram a complexidade de suas ações.

Dentre as atribuições do nutricionista no PNAE estão, por exemplo, a realização de testes de aceitabilidade, o monitoramento do estado nutricional e a elaboração de cardápios diferenciados por faixa etária e para escolares que necessitam de atenção específica ${ }^{9,17}$. Sabe-se que o cumprimento das atribuições técnicas do nutricionista no PNAE relaciona-se ao quantitativo de profissionais no Programa. Não obstante esse importante avanço em termos de cobertura profissional, faz-se necessário atentar que $20 \%$ dos municípios ainda conviviam com a ausência do profissional em 2011. Vale destacar também que esse estudo não objetivou verificar a adequação do número de profissionais em cada EE com registro de nutricionista em relação ao número de alunos, conforme os parâmetros da Resolução CFN no $465 / 2010^{17}$. Esse é certamente um ponto de importante investigação em estudos futuros e um provável motivo do não cumprimento de todas as atribuições previstas para o profissional, estando este, possivelmente, sobrecarregado quando não há o atendimento do parâmetro numérico mínimo estabelecido.

Ainda em relação à cobertura de profissionais, atenta-se para a importância de mecanismos que garantam a inserção do profissional no universo dos municípios do país. Observou-se desigualdade regional quanto à distribuição dos profissionais cadastrados no FNDE/MEC. Dentre as 27 Unidades Federativas do país, somente $11(40 \%)$ apresentaram mais de $80 \%$ de seus municípios cobertos por nutricionista cadastrado no FNDE/PNAE. Um exemplo positivo nesse sentido seria a Região Sul do Brasil, que apresentou seus três estados (Paraná, Santa Catarina, e Rio Grande do Sul) com percentuais de cobertura $>80 \%$. A Região Norte, por sua vez, não alcançou esse percentual para nenhum de seus sete estados. Três deles mostraram percentuais de cobertura acima de 70\% (Acre, Pará e Rondônia), enquanto que estados como Amapá e Tocantins indicaram percentuais abaixo de $50 \%$. Na 
Região Nordeste, o Estado de Pernambuco também mostrou um percentual preocupante $(16,8 \%)$, sendo esse o mais baixo dentre todas as Unidades Federativas do Brasil.

Esses achados relacionam-se a questões sociais importantes, sendo fundamental refletir e agir sobre as mesmas, com vistas à maior uniformidade entre as regiões brasileiras. As regiões com menor percentual de cobertura profissional são justamente aquelas que convivem mais intensamente com desequilíbrios nutricionais. Vale registrar que os dados coletados pela Pesquisa Nacional por Amostra de Domicílios (PNAD) ${ }^{19}$, em 2009, para estimar a magnitude da insegurança alimentar nos domicílios brasileiros, apontaram as regiões Nordeste e Norte como aquelas com maior percentual de domicílios particulares em situação de segurança alimentar (53,9\% e $59,7 \%$, respectivamente). O melhor percentual foi atribuído a Região Sul $(81,3 \%)^{19}$. Nesse sentido, são necessárias medidas de proteção principalmente para as localidades mais carentes, onde a população está amplamente exposta à dupla carga de morbidade nutricional, com a coexistência de desnutrição e obesidade. Vale ressaltar os achados da Pesquisa Nacional de Saúde do Escolar (2009), que identificou 23\% dos escolares do ensino fundamental das capitais brasileiras em situação de excesso de peso ${ }^{20}$.

Ainda em relação ao desequilíbrio observado na cobertura de nutricionista nas regiões do país, algumas questões importantes são levantadas: será que nas regiões com os maiores percentuais de cobertura os CRNs estariam mais atuantes, ou ainda os gestores mais comprometidos com o enfoque do PNAE? Ou a própria categoria profissional estaria mais mobilizada, no intuito de pressionar os governantes na contratação de profissionais? Ou ainda, será que a distribuição dos cursos de graduação em nutrição está mais concentrada nas regiões de maior cobertura do profissional no Progra$m a$ ? Esses são pontos de importante reflexão e averiguação, com vistas ao equilíbrio e ao atendimento das legislações em vigor em todo o território nacional.

Alguns autores ${ }^{21,22}$ relatam a dificuldade do nutricionista em exercer todas as suas atividades técnicas. Segundo Motta et al. ${ }^{21}$, o nutricionista foi condicionado na sua formação a olhar para a saúde de forma estanque e não numa abordagem complexa e multidimensional.

Apesar do conhecimento das suas atribuições, o nutricionista enfrenta barreiras na execução, pois são muitas vezes sobrecarregados por atividades burocráticas e administrativas. Atividades complexas e que, consequentemente, necessitam de disponibilidade de materiais e de outros profissionais de apoio, tais como a execução da avaliação nutricional, testes de aceitabilidade e atividades de educação alimentar e nutricional, são negligenciadas em detrimento da urgência do trabalho administrativo que o nutricionista também exerce ${ }^{23}$.

Uma forma de contornar essas dificuldades poderia ser a realização, pelos nutricionistas, do matriciamento de outros profissionais envolvidos direta ou indiretamente no Programa, como manipuladores de alimentos, professores, educadores físicos, técnicos administrativos e demais membros da comunidade escolar, como pais e alunos, de forma a compartilhar práticas e saberes em nutrição e saúde. Esta prática possibilita que os envolvidos incorporem em seu campo de conhecimento aspectos antes delegados a especialistas, ampliando sua capacidade de resolver problemas e identificando com mais sensibilidade e precisão os casos que necessitam de apoio especializado $^{24}$. Salienta-se que a proposta de matriciamento surgiu no final da década de 1990 na atenção básica com o objetivo de aumentar o grau de resolubilidade das ações de saúde. Ela propõe uma reformulação no modo de organização dos serviços e relações horizontais entre as especialidades que passam a oferecer apoio técnico horizontal às equipes interdisciplinares de atenção básica, favorecendo assim a conexão em rede $e^{25}$.

Muito utilizado em saúde, o apoio matricial objetiva assegurar, de um modo dinâmico e interativo, a retaguarda especializada aos profissionais de referência, em duas dimensões: suporte assistencial e técnico-pedagógico. Este seria um caminho para que o nutricionista do PNAE pudesse concretizar na prática suas atividades técnicas, comumente negligenciadas, uma vez que ampliaria a capacidade de outros profissionais envolvidos direta ou indiretamente no Programa resolverem situações comuns, antes concentrados no especialista, permitindo que esse atue de forma mais específica. Nessa mesma linha, Domene $^{26}$ ressalta que o trabalho interdisciplinar exige um esforço contrário ao caminho traçado pela especialidade para que se supere a tangência entre os saberes. Destaca-se que a adoção da estratégia de matriciamento no PNAE deve ser vista como uma possibilidade de ampliação das ações e não como um meio de suprir a falta do profissional.

Ainda com vistas ao cumprimento dos princípios e diretrizes do Programa, o FNDE, por sua vez, deve manter seu papel de órgão fomen- 
tador, normatizador e fiscalizador do cumprimento da legislação do PNAE por parte dos gestores, até mesmo aplicando penalidades previstas para aquelas EE que descumpram algum item exigido pelas normativas em vigor, em especial o não cumprimento da previsão de nutricionistas como RT do Programa. Um dos importantes mecanismos criados pelo FNDE para potencializar a execução do PNAE nas escolas públicas e filantrópicas na educação básica brasileira refere-se à criação dos Centros Colaboradores em Alimentação e Nutrição do Escolar (CECANE) ${ }^{27}$, os quais formam uma rede interinstitucional que presta apoio técnico e operacional aos estados e municípios na implementação da alimentação saudável nas escolas.

Reforçando as ações, o sistema CFN/CRN deve continuar realizando sua missão de orientação e fiscalização do exercício profissional, para que os nutricionistas já atuantes no PNAE possam cumprir suas atribuições, bem como cobrar dos gestores a adequação do parâmetro numérico e, quando necessário, procurar outros órgãos de controle para que se faça cumprir a Resolução CFN no $465 / 2010^{17}$.

Destaca-se que, em 2011, a coordenação responsável pelo cadastramento no FNDE iniciou ações de aperfeiçoamento e atualização do SINUTRI, com vistas a solicitar dos gestores das EE providências em cujo município não constava o nutricionista, bem como naqueles que o profissional já tenha se desvinculado e não realizou o descadastramento no FNDE. Ainda nesse sentido, em abril de 2012, houve a disponibiliza-

\section{Colaboradores}

LG Chaves, TCM Santana, CG Gabriel e FAG Vasconcelos participaram da concepção e desenho do artigo, redação e revisão do texto.

\section{Agradecimentos}

Ao Fundo Nacional de Desenvolvimento da Educação (FNDE), a partir de parceria estabelecida com o Centro Colaborador em Alimentação e Nutrição do Escolar do Estado de Santa Catarina (CECANE/SC). ção do Sistema na versão online, no sítio eletrônico do FNDE, com intuito de continuidade da atualização do banco de dados do cadastramento dos profissionais e visualização pelos profissionais e gestores da situação desse cadastro. Espera-se que essas ações possibilitem uma quantificação mais precisa do universo de profissionais envolvidos no PNAE.

\section{Considerações finais}

Os resultados apresentados neste artigo indicam que o quantitativo de municípios brasileiros com nutricionistas cadastrados no SINUTRI/FNDE evoluiu no período de 2003 a 2011. A despeito dos muitos avanços na legislação do PNAE, observa-se ainda certa desigualdade na distribuição dos nutricionistas entre as regiões do Brasil, sendo a Região Norte aquela com menor percentual de municípios cobertos por nutricionistas em 2011.

As diretrizes e os princípios do PNAE mostram que sua execução é complexa e que extrapola o entendimento usual de que o Programa serve apenas para fornecer alimentação saudável às crianças. As diversas atividades do profissional no Programa indicam a necessidade de constante atualização e formação do nutricionista atuante no PNAE, com concomitante necessidade do cumprimento e fiscalização dos parâmetros numéricos de referência para contratação de nutricionistas nos distintos municípios e estados brasileiros.

\section{Referências}

1. Brasil. Decreto no 37.106 de 31 de março de 1955 . Institui a Campanha de Merenda Escolar. Diário Oficial da União 1955; 31 mar.

2. Spinelli MAS, Canesqui AM. O programa de alimentação escolar no estado de Mato Grosso: da centralização à descentralização (1979 - 1995). Rev Nutr 2002; 15(Supl. 1):105-117.

3. Peixinho AML, Abranches J, Barbosa NVS. Políticas de Alimentação Escolar a partir da Estratégia Fome Zero. In: Ministério do Desenvolvimento Social e Combate à Fome. Fome Zero: Uma História Brasileira. Brasília: Ministério do Desenvolvimento Social e Combate à Fome, Assessoria Fome Zero; 2010. v.2. p. 93-103. 
4. Brasil. Ministério da Educação. Fundo Nacional de Desenvolvimento da Educação [Internet]. Alimen tação escolar. [acessado 2012 fev 22]. Disponível em: http://www.fnde.gov.br/index.php/programasalimentacao-escolar.

5. Brasil. Conselho Nacional de Segurança Alimentar e Nutricional [Internet]. Indicadores de Segurança Alimentar e Nutricional - 2010. [acessado 2012 fev 22]. Disponível em: http://www4.planalto.gov.br/consea/ destaque/indicadores-de-seguranca-alimentar-enutricional.

6. Brasil. Lei no 8.913 de 12 de julho de 1994. Dispõe sobre a municipalização da merenda escolar. Diário Oficial da União 1994; 12 jul.

7. Brasil. Resolução/FNDE/CD/n 32 de 10 de agosto de 2006. Estabelece as normas para a execução do Programa Nacional de Alimentação Escolar. Diário Oficial da União 2006; 10 ago.

8. Brasil. Lei $n^{\circ} 11.947$ de 16 de julho de 2009. Dispõe sobre o atendimento da alimentação escolar e do Programa Dinheiro Direto na Escola aos alunos da educação básica. Diário Oficial da União 2009; 16 jun.

9. Brasil. Resolução/CD/FNDE no 38 de 16 de julho de 2009. Dispõe sobre o atendimento da alimentação escolar aos alunos da educação básica no Programa Nacional de Alimentação Escolar (PNAE). Diário Oficial da União 2009; 16 jun.

10. Coimbra M, Meira JFP, Starling MBL. Comer e apren der: uma história da alimentação escolar no Brasil. Belo Horizonte: MEC, INAE; 1982.

11. L'Abbate S. As Políticas de Alimentação e Nutrição no Brasil: I. Período de 1940 a 1964. Rev Nutr 1988; 1(Supl. 2):87-138

12. Vasconcelos FAG. Os Arquivos Brasileiros de Nutrição: Uma Revisão sobre Produção Científica em Nutrição no Brasil (1944 a 1968). Cad Saude Publica 1999; 15(Supl. 2):303-316.

13. Vasconcelos FAG, Calado CLA. Profissão nutricionista: 70 anos de história no Brasil. Rev Nutr 2011 24(Supl. 4):605-617.

14. Brasil. Medida Provisória 2.178-36 de 24 de agosto de 2001. Dispõe sobre o repasse de recursos financeiros do Programa Nacional de Alimentação Escolar, institui o Programa Dinheiro Direto na Escola, altera a Lei no 9.533, de 10 de dezembro de 1997, que dispõe sobre programa de garantia de renda mínima, institui programas de apoio da União às ações dos Estados e Municípios, voltadas para o atendimento educacional, e dá outras providências. Diário Oficial da União 2001; 24 ago.

15. Brasil. Presidência da República. Fome Zero. [Internet]. 2012. [acessado $2012 \mathrm{fev}$ 27]. Disponível em: http://www.fomezero.gov.br/

16. Brasil. Conselho Federal de Nutricionistas. Resolução/CFN no 358 de 18 de maio de 2005. Dispõe sobre as atribuições do nutricionista em âmbito do programa de alimentação escolar (PNAE) e dá outras providências. Diário Oficial da União 2005; 18 mai.
17. Brasil. Conselho Federal de Nutricionistas. Resolução/CFN no 465 de 23 de agosto de 2010. Dispõe sobre as atribuições do Nutricionista, estabelece parâmetros numéricos mínimos de referência no âmbito do Programa de Alimentação Escolar (PAE) e dá outras providências. Diário Oficial da União 2010; 16 jun.

18. Brasil. Conselho Federal de Nutricionistas. Resolução/CFN n ${ }^{\circ} 380$ de 28 de dezembro de 2005. Dis põe sobre a definição das áreas de atuação do nutricionista e suas atribuições, estabelece parâmetros numéricos de referência por área de atuação e dá outras providências. Diário Oficial da União 2005; $28 \mathrm{dez}$

19. Brasil. Instituto Brasileiro de Geografia e Estatística. Pesquisa Nacional por Amostra de Domicílios. Segurança Alimentar. 2004/2009. [Internet]. 2010. [acessado 2012 mar 03]. Disponível em: http://www. ibge.gov.br/home/estatistica/populacao/seguranca_ alimentar_2004_2009/pnadalimentar.pdf

20. Brasil. Instituto Brasileiro de Geografia e Estatística (IBGE). Diretoria Pesquisa Nacional de Saúde do Escolar 2009. Avaliação do Estado Nutricional dos Escolares do 9o Ano do Ensino Fundamental - Municípios das Capitais e Distrito Federal. Rio de Janeiro, 2010. [Internet]. 2009. [acessado 2012 jun 26]. Disponível em: http://www.ibge.gov.br/home/estatistica/ populacao/pense_avaliacao_nutricional_2009/ pense_avaliacao_nutricional_2009.pdf

21. Motta DG, Oliveira MRM, Boog MCF. A formação universitária em nutrição. Pro-Posições 2003; 14(Supl. 1):69-86.

22. Franco AC, Boog MCF. Relação teoria-prática no ensino de educação nutricional. Rev Nutr 2007; 20(Supl. 6):643-655.

23. Mello AL, Vidal JPO, Sampaio LR, Santos LAS, Freitas MCS, Fontes GAV. Perfil do nutricionista do programa nacional de alimentação escolar na região Nordeste do Brasil. Rev Nutr 2012; 25(Supl. 1):119-132.

24. Brasil. Ministério da Saúde (MS). Secretaria de Atenção à Saúde. Departamento de Atenção Básica. Cadernos de atenção básica. Saúde na escola. Brasília: MS; 2009.

25. Sousa FSP, Jorge MSB, Vasconcelos MGF, Barros MMM, Quinderé PHD, Gondim LGF. Tecendo a rede assistencial em saúde mental com a ferramenta matricial. Physis 2011; 21(Supl. 4):1579-1599.

26. Domene SMA. A escola como ambiente de promoção da saúde e educação nutricional. Psicologia 2008 19(Supl. 4):505-517.

27. Brasil. Rede Brasileira de Alimentação e Nutrição do Escolar. Centros Colaboradores. [Internet]. 2012. [acessado 2012 mar 03]. Disponível em: http://www. rebrae.com.br/centros colaboradores.html

Artigo apresentado em 03/01/2013

Aprovado em 05/01/2013

Versão final apresentada em 08/01/2013 